\title{
Erratum to: Diversity and Community Structure of Archaea in Deep Subsurface Sediments from the Tropical Western Pacific
}

Wei Zhang • Gaowa Saren • Tiegang Li •

Xinke Yu $\cdot$ Linbao Zhang

Published online: 28 March 2010

(C) Springer Science+Business Media, LLC 2010

\section{Erratum to: Curr Microbiol}

DOI 10.1007/s00284-009-9562-0

The second institution of the authors, W. Zhang and L. Zhang was inadvertently not published in the original article. The complete information of the authors is included below.

\begin{abstract}
Acknowledgement The work was financially supported by the Pilot Projects of Knowledge Innovation Project of Chinese Academy of Sciences grants (KZCX2-YW-211-03, KZCX2-YW-JC201 and MGE2008KG06).
\end{abstract}

The online version of the original article can be found under doi:10.1007/s00284-009-9562-0.

W. Zhang · G. Saren · T. Li · X. Yu ( $₫) \cdot$ L. Zhang

Key Laboratory of Marine Geology and Environment, Institute of Oceanology, Chinese Academy of Sciences, Qingdao 266071,

China

e-mail: xyu@ms.qdio.ac.cn

W. Zhang

e-mail: zw2326cs@163.com

W. Zhang - L. Zhang

Graduate University, Chinese Academy of Sciences,

Beijing 100049, China 